\title{
AEROgui \\ A Graphical User Interface for the Optical Properties of Aerosols
}

\author{
by R. Pedrós, J.L. Gómez-Amo, C.R. Marcos, M.P. Utrillas, \\ S. Gandía, F. Tena, and J.A. Martinez Lozano
}

\section{A tool that simulates realistic aerosol scenarios for climatic applications is presented and discussed.}

A erosols have an uncertain effect on climate (Alexander et al. 2013) and serious impacts on human health (Nel 2005). Aerosols directly affect climate by modifying Earth's energy budget, known as radiative forcing. A net positive forcing tends to heat Earth, while a negative forcing tends to cool it down. Aerosols also modify cloud microphysical properties and albedo and thus impact precipitation (indirect radiative effects). For example, Saharan and Asian dust and biological aerosols probably serve as ice nuclei and play an important role in orographic precipitation

affiliations: Pedrós, Marcos, Utrillas, Gandía, Tena, and Martinez Lozano-Solar Radiation Group, Earth Physics Department, University of Valencia, Valencia, Spain; GómEzAmo-Solar Radiation Group, Earth Physics Department, University of Valencia, Valencia, Spain, and Laboratory of Earth Observations and Analyses, ENEA, Rome, Italy CORRESPONDING AUTHOR: Roberto Pedrós, Earth Physics Department, University of Valencia, C/Dr Moliner 50, 46100 Burjassot, Spain

E-mail: pedrose@uv.es

The abstract for this article can be found in this issue, following the table of contents.

DOI:10.1175/BAMS-D-13-00162.1

A supplement to this article is available online (10.II75/BAMS-D-13-00162.2)

In final form 15 April 2014

(C)2014 American Meteorological Society processes over the western United States (Creamean et al. 2013). In addition, aerosols interact with other elements of the Earth system. For instance, mineral dust aerosols are a source of iron for ocean biogeochemistry, the deposition of mineral dust and black carbon (BC) aerosols decreases the albedo of snow and ice, and aerosol influences vegetation growth by modifying the photosynthetically active radiation [Bellouin et al. (2011); and references therein].

Because aerosols are not well mixed throughout the atmosphere, simulations are one of the only methods of estimating their average climate effect (Myhre et al. 2013), the other method involving interpretation of satellite and ground-based measurements (Holben et al. 1998; Remer et al. 2008). The radiative forcing of the total aerosol effect in the atmosphere, which includes cloud adjustments due to aerosols, is $-0.9 \mathrm{~W} \mathrm{~m}^{-2}$ (from -1.9 to $-0.1 \mathrm{~W} \mathrm{~m}^{-2}$ ) (medium confidence). There is a negative forcing from most aerosols and a positive contribution from black carbon absorption of solar radiation (Alexander et al. 2013). The main cause of the uncertainty is the differences between estimates from global aerosol models and observation-based estimates, with the latter tending to have stronger (more negative) radiative forcing (Myhre 2009). Since radiative forcing estimates from observational data are currently not possible, they must, at least partly, rely on global aerosol models (Myhre 2009). 
An additional source of uncertainty is the aerosols' altitude. Samset and Myhre (2011) analyzed the sensitivity with the aerosol vertical distribution of the normalized direct radiative forcing (NDRF) - that is, direct radiative forcing divided by the burden $\left(\mathrm{mg} \mathrm{m}^{-2}\right)$. The authors found a tenfold increase in the NDRF for BC close to the surface and the lower part of the stratosphere.

On the other hand, aerosols experience physical and chemical transformations in the time they spend in the atmosphere, known as aging, which modifies their optical properties. In particular, aerosols change their mixing state as they age. Aerosols can be externally mixed, which means that different aerosol components exist separately. In other words, there is no physical or chemical interaction between the aerosol components. Alternatively, aerosols can be internally mixed when they interact with other particles during their residence time in the atmosphere. Internal mixture can be described as an absorbing core surrounded by a shell of negligibly absorbing material. This approach is particularly relevant for internally mixed BC particles, since they are estimated to be the second most significant component of global warming after $\mathrm{CO}_{2}$ in terms of modifying the energy balance at the ground level (Ramanathan and Carmichael 2008). Moreover, the knowledge of the aerosol mixing state provides information on sources, transformation, and aging processes of the aerosol population. For instance, Wang and Martin (2007) detected that the change from internal to external mixing for the insoluble and soluble materials changed the single-scattering albedo, the aerosol optical depth, and the aerosol radius.

In this paper, we present a simple and fast-running software package to compute the aerosol optical properties. This tool can help to simulate realistic aerosol scenarios and to improve the global aerosol models that are very expensive in computation time. The software package AEROgui includes the more relevant models for external and internal mixing and offers the flexibility to include user-defined size distributions and refractive indices of aerosols. We have used AEROgui to carry out several sensitivity analyses that stress the importance of internal mixing in absorption and scattering of aerosols. Model outputs concur with measurements for several aerosol scenarios. In particular, we have examined the sulfate modulation of $\mathrm{BC}$ absorption on coastal environments. The supplemental material (available online at http://dx.doi.org/I0.II75/BAMS-D-I3-00162.2) also includes more comparisons, including the aging of mineral dust.

\section{OVERVIEW OF THE GRAPHICAL USER} INTERFACE. The AEROgui graphical user interface presented here has been developed in MATLAB R2013b. The interface can run in two different ways: atmosphere mode and batch mode. The output properties are extinction, scattering, and absorption coefficients; single-scattering albedo; asymmetry parameter; and aerosol optical depth (in the atmospheric mode). The outputs are described with more detail in the section on output optical properties. The interface includes the possibility of internally mixing the aerosol components, meaning that the two components are contained in a single particle. The software package includes several procedures to describe the internal mixture. For more details, see the section on aerosol mixing.

The atmosphere mode allows modeling the optical properties of a combination of aerosol components, which can be combined internally or externally, in up to four atmospheric layers. The user has to supply the particle density of the selected aerosol components. The atmospheric mode has four parts: (i) atmospheric layer selection, (ii) external mixture selection, (iii) internal mixture selection, (iv) relative humidity selection, and (v) output selection. The layer selection allows inputting aerosol information in up to four strata: the mixing layer, dust layer (included to account for the mineral dust transported over long distances), free troposphere, and stratosphere. The user has to select the components of each layer, and whether they are in external or internal mixture. Once the component is selected, the user has to select its particle density. The interface includes for each component a preset refractive index, as well as radius and width of a lognormal size distribution. Moreover, the user can also include custom values of the refractive index and the lognormal size distribution in up to nine possible size bins.

Alternatively to the atmospheric mode, the user can work in batch mode to automate the execution. The outputs of the batch mode are the optical properties of the internally mixed aerosols, as well as the absorption amplification - that is, the ratio of the absorption coefficient of the internally mixed aerosol and the absorption coefficient of the pure core component. The batch mode permits the exhaustive calculation of the optical properties of several aerosol components in internal mixture for sensitivity studies. Moreover, the batch mode could also be used to invert the Mie model to infer properties of the atmospheric aerosols by using measured optical properties.

The user can select between the output units in meters squared per gram or meters squared per 
kilometer. In the first case, the user has to provide the particle density of each selected component, so that the total sum for all components will be normalized to 1 . Alternatively, the user has to supply the particle density per centimeters cubed, if units per kilometer are selected.

The aerosol software package that we present is an update of the aerosol module of Optical Properties of Aerosols and Clouds (OPAC) (Hess et al. 1998). OPAC consists on a dataset of optical properties of 10 aerosol components, which were considered as typical, and stored as ASCII files. A FORTRAN program serves to extract the optical properties of the components, which were previously computed using the Mie scattering of homogenous spheres. The aerosols components can only be externally mixed and are predefined, so the size distribution parameters and the refractive index cannot be changed. Notwithstanding this, OPAC is a valuable tool to model the optical properties of aerosols and is still used in many domains such as remote sensing, air quality, photobiology, or astrophysics.

Levoni et al. (1997) also presented a database of optical properties of several components in external and internal mixing. Nevertheless, the aerosol components were predefined and the internal mixing only included the volume-weighted linear average of refractive indices. Similarly, other authors have developed their own tools to model aerosol optical properties by choosing particular mixing rules and selecting the size distribution parameters and refractive indices (e.g., Ramachandran and Srivastava 2013; Ma et al. 2012; Yu et al. 2012; Aquila et al. 2011; Aouizerats et al. 2010; Bauer et al. 2008; Stier et al. 2007) but not making these tools available to the scientific community.

AEROSOL COMPONENTS. Aerosol particles result from different sources and processes. At any place in the atmosphere there exists a mixture-or composite-of particles of different origin. To describe the wide range of possible compositions, the aerosol particles are modeled as a combination of basic elements or components. The external mixture selection permits combining several aerosol components without physical or chemical interaction between them. The aerosol components we consider are $\mathrm{BC}$, hydrophilic and hydrophobic organic carbon (OC), nitrate, sulfate, sea salt, biomass burning (BB), and dust. Each aerosol component is described by an individual particle size distribution and spectral refractive index. The number size distribution is considered in two lognormal modes-fine and coarse-with two relevant parameters each: the geometric-mean radius and the geometric standard deviation. Biomass is the exception of the fine and coarse modes, since we consider in this case fresh and aged particles. The atmosphere mode of the interface includes literature values for the size distribution parameters, although the user can input different ones in up to nine size bins.

The particles are considered to be spherical so that the classical Mie theory can be applied, although it is known that the exact shape and the orientation of the particles can significantly influence the radiative properties. Some results show that ignoring nonsphericity will lead to underestimation of the regional warming and dust absorption efficiency (Mishra et al. 2008). Notwithstanding, the results should not be completely misguided for the bigger dust radii, since in this case the difference between spherical and nonspherical absorption cross sections are calculated to be only about 2\% (Mishchenko et al. 1997). We will consider aerosol nonsphericity in the near future, taking advantage of the existing databases available in the literature (e.g., Meng et al. 2010).

Water is important too, since it is ubiquitous in the atmosphere and interacts with aerosols. Therefore, the aerosol effects on climate also depend on the aerosol interaction with water and on its availability. For this, the relative humidity change has been taken into account in the interface. Relative humidity increases affect hygroscopic aerosols-nitrate, sulfate, sea salt, and a fraction of the organic carbon-in a two fold way. On the one hand, an increase in relative humidity makes the particle size grow. On the other hand, it affects the hygroscopic aerosols optical properties by modifying the refractive index. As a result, the extinction coefficient increases with relative humidity (Bellouin et al. 2007). Hence, hydrated aerosols will exert larger radiative perturbation than their dry counterparts. The hygroscopic growth of sea salt is described using a parameterization as a function of relative humidity by Gerber (1985). For the rest of hydrophilic components (sulfate, nitrate, and hydrophilic OC), the growth is described with the Köhler equation (Köhler 1936; Chylek and Wong 1998; Wex et al. 2008). The approach for the variation in the refractive index has been either based on measurements (sea salt, sulfate, and nitrate) or using the volume-weighted average of the refractive indices of pure water and the dry aerosol (hydrophilic OC). Alternatively, the interface incorporates the possibility to include a user-defined growth value and refractive index. Hygroscopic growth also affects the mass density of the aerosol component. The mass 
density increase with relative humidity is calculated using a volume-weighted average of the densities of the component and pure water.

More details on the aerosol components have been included in the online supplemental information.

AEROSOL MIXING. Aerosols can be externally mixed, which means that different aerosol components exist separately. In other words, there is no physical or chemical interaction between the aerosol components. The radiative properties in this case are modeled on the basis of weighted sums of the radiative properties of the individual aerosol components.

Alternatively, aerosols can be internally mixed, with climate-relevant effects. For instance, internally mixed $\mathrm{BC}$ particles are estimated to be the second most significant component of global warming after $\mathrm{CO}_{2}$ in terms of direct radiative forcing (Jacobson 2001; Ramanathan and Carmichael 2008). Nevertheless, the term internal mixture has several meanings. It can represent a homogeneous population of homogeneous particles, where the strongly absorbing material is perfectly mixed with other material at the molecular level (also named volume mixing). An internal mixture may also refer to an absorbing core surrounded by a shell of negligibly absorbing material. Such descriptions imply a concentricity that may not exist (Bond and Bergstron 2006). Notwithstanding, Jacobson (2000) and Bond et al. (2006) have suggested that for internally mixed $\mathrm{BC}$ particles a concentric sphere geometry is more plausible.

The scattering of a plane, monochromatic, electromagnetic wave by a homogeneous, dielectric sphere is described by Mie's solution to Maxwell's equations using the aerosol complex index of refraction and a size distribution. We use the well-proven numerical code for the Mie calculations by Bohren and Huffman (1983) in its MATLAB implementation by Mätzler (2002)

Another approach to describe internal mixing is to consider mixing rules to calculate the effective refractive indices of the mixture and use Mie scattering calculations. There are several mixing rules commonly used in the literature: 1) molar refraction and absorption, 2) volume-weighted linear average of the refractive indices, 3) Maxwell-Garnett rule, 4) dynamic effective approximation, and 5) Bruggeman rule (Abo Riziq et al. 2007; Stier et al. 2007; and references therein). According to some authors, the Maxwell-Garnett rule is appropriate for the inclusion of an insoluble core in a liquid host, and the Bruggeman rule is the more suited for internal mixtures of solid compounds (Chýlek et al. 2000; Lesins et al. 2002).

On the other hand, Abo Riziq et al. (2007) used mixing rules 1-4 and the shell-and-core approach to predict radiative properties of aerosols of mixed composition and compared them with cavity ring down spectrometry measurements. The results of the comparison for nonabsorbing mixtures suggested that the linear mixing rule is the best way to predict the index of refraction. However, the other mixing procedures also provided very good agreement with the measured values. For absorbing mixture with the low fraction of the absorbing material, all mixing rules showed similar results, though the shell-andcore model was slightly closer to the measured values. Schuster et al. (2005) found similar agreement when applying the shell-and-core and the Maxwell-Garnet rules to urban-industrial climatologies. They found higher absorption for the shell-and-core configuration because this situation corresponds to small absorbing cores, which are more efficient absorbers than eccentric cores (Fuller et al. 1999). Regarding absorbing mixtures with relatively high volume fractions, Abo Riziq et al. (2007) found that no mixing rule or model was an excellent match to measurements. And, along the same line, Cappa et al. (2012) pointed out that the shell-and-core internal mixture might not be appropriate to model the optical properties of ambient BC particles. As a consequence, their conclusions challenged the predictions of several aerosol models (Jacobson 2001; Chung and Seinfeld 2005), which could overestimate the atmospheric warming of $\mathrm{BC}$ by a factor up to 2 .

We have included the five above-mentioned mixing rules in the batch mode. Thus, the effective refractive indices calculated with these mixing rules can be used to define a new component for the atmospheric mode.

Besides choosing the most appropriate mixing approach, we have to bear in mind that the selection of the density and refractive index of the component is a major source of error in the climate modeling (Bond and Bergstrom 2006). Therefore, the software package includes the possibility of changing these parameters.

OUTPUT OPTICAL PROPERTIES. The software package can calculate the following optical properties of aerosols: extinction coefficient, scattering coefficient, absorption coefficient, singlescattering albedo (SSA), asymmetry parameter, and aerosol optical depth (AOD). The outputs are calculated in the wavelength range $[0.3,4.0] \mathrm{mm}$, in 0.05 steps below $1 \mu \mathrm{m}$, and 0.25 steps above $1 \mu \mathrm{m}$. 
The scattering cross coefficient is related to the probability of light being scattered by an aerosol. Analogously, the absorption coefficient is related to the probability of absorption. The sum of these coefficients results in the extinction coefficient.

The internal subroutines of the interface calculate the scattering, absorption, and extinction coefficients $\left(\mathrm{km}^{-1}\right)$ normalized to a number density of 1 particle per cubic centimeter for each component. The absolute values of the coefficients can be calculated by multiplying them with the appropriate particle density. When several aerosol components are considered to form a composite aerosol in the atmospheric layer, the resulting coefficient is the sum of the absolute values of the component coefficients. For this calculation, an aerosol component can be a pure component but also the result of an internal mixture of components.

On the other hand, the output can be mass coefficients, also named specific coefficients or mass efficiencies $\left(\mathrm{m}^{2} \mathrm{~g}^{-1}\right)$. They correspond to optical cross sections per mass of the particle or the core particle when we consider the shell-and-core internal mixture. The calculation requires the mass density of the aerosol component-either the default value or a user-supplied one.

The software package also supplies the SSA, which is the key parameter to understanding the influence of different aerosol types on the radiative balance (Hansen et al. 1997). The SSA of a single particle is defined as the ratio of the scattering coefficient to the extinction coefficient. The SSA of the composite aerosol is obtained by the sum of those of the aerosol components, weighted with the product of each particle density and extinction coefficient, and then normalizing to the extinction coefficient of the composite. The interpretation of the SSA is that for SSA $=1$ the aerosol is totally scattering. As a consequence, the aerosol will tend to lower the global-mean surface temperature. This is the case of sea salt and sulfate aerosol. On the other hand, strongly absorbent aerosols, such as BC, can have a value as low as 0.2. The batch mode of the software package can be used to perform sensitivity studies. As an example, we have analyzed the SSA variation of the $\mathrm{BC}$ of two different sizes when coated with OC in the shell-and-core internal mixing. The SSA of OC-coated BC for core radius $0.2 \mu \mathrm{m}$ initially shows a steep increase when the sulfate coating dwells. However, for a coating radius of about $1 \mu \mathrm{m}$, the SSA remains fairly constant, and very close to 1 (Fig. 1a), meaning that the aerosol is almost totally scattering. On the other hand, when the $\mathrm{BC}$ core radius is $2 \mu \mathrm{m}$, the SSA exhibits a certain
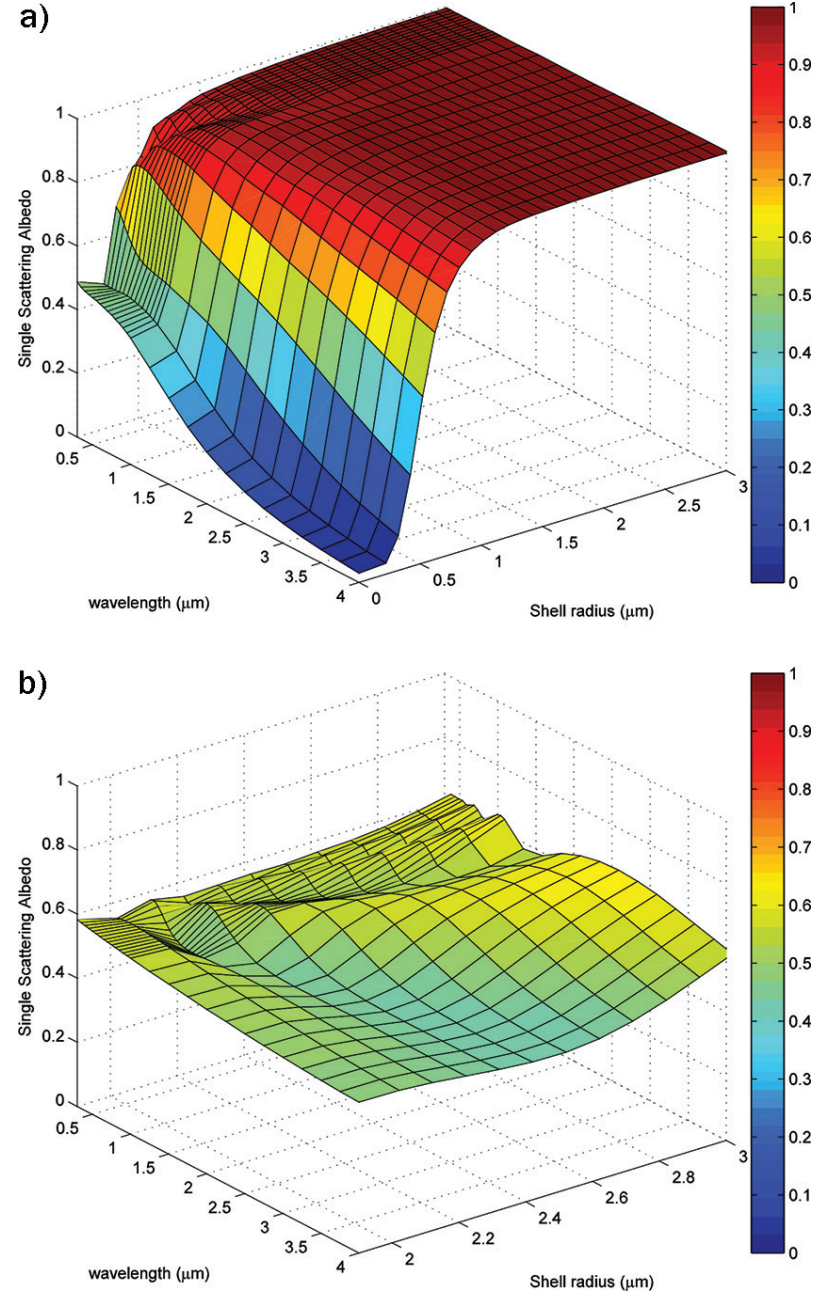

FIG. I. SSA of sulfate-coated BC for several shell radii for $B C$ radius (a) 0.2 and (b) $2 \mu \mathrm{m}$. The pure BC SSA is shown for comparison in both panels as a cornice on the left border of the surface. The relative humidity is $\mathbf{5 0} \%$.

variation, but the values are not very different from those of pure BC (Fig. 1b). Additionally, the SSA is nearly constant with the increase in relative humidity, as the scattering increases and the absorption decreases almost in the same proportion (not shown in the figure). More sensitivity studies can be found in the supplementary material available online.

The value of SSA is important as there is a threshold SSA (King et al. 1999). Below that threshold, aerosol will increase the global-mean surface temperature. This lower threshold depends mostly on the underlying surface reflectance (or brightness) and less on the aerosol burden (Bellouin et al. 2007). The brighter the surface, the larger the critical SSA is. Therefore, it is easier to have positive radiative perturbations over bright surfaces such as deserts, ice-covered areas, and clouds. 
Another output of the interface is the asymmetry parameter $g$. Since the radiation scattered by aerosols is asymmetrical, the phase function describes the angular distribution of radiation scattered by a particle or by particles composing an aerosol composite. In practice, the phase function is parameterized with only the parameter $g$, which is the mean cosine of the scattering angle, found by integration over the complete scattering phase function. The interpretations of the asymmetry factor is that for $g=1$, the aerosol completely scatters in the forward direction, whereas $g=0$ denotes symmetric scattering. For spherical particles, $g$ is related to particle size in a systematic way: the larger the particle size, the more the scattering in the forward hemisphere.

Finally, the AOD is considered to be the simplest and most representative parameter for characterizing the aerosols present in the atmosphere. The AOD calculation, based on the Bouguer-Lambert-Beer law, is the result of integrating the aerosol extinction coefficient (per kilometer) over the entire atmosphere, which is the sum of several possible layers. For this, the distribution of aerosol particles with the height for each layer is described by means of exponential profiles given by

$$
N(h)=N(0) e^{-h / Z},
$$

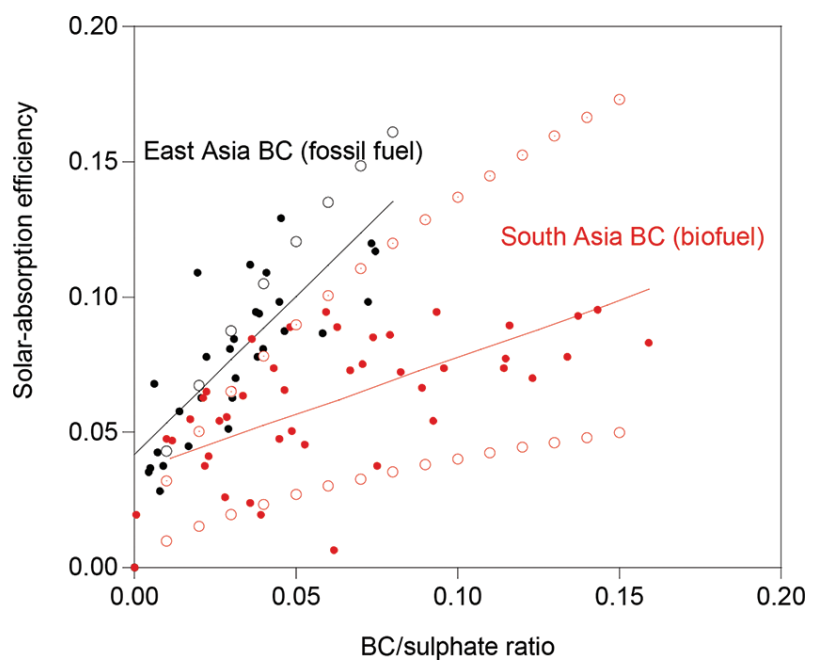

FIG. 2. BC-to-sulfate mass concentration vs aerosol solar absorption efficiency at the wavelength $0.550 \mu \mathrm{m}$. The solid dots correspond to the measurements taken from Ramana et al. (2010). The continuous lines are the best-fit lines for these measurements. The open dots correspond to the model runs, consisting of an internal mixing of sulfate with different cores: I) for the black open dot, the core is BC; 2 ) for the red open dot, the core is palm oil biofuel; and 3 ) the red-circled dot corresponds to a core of aged biomass fuel. where $h$ is the altitude (in kilometers) of the layer, $N(0)$ is the particle density at the bottom of the layer, and $Z$ tis he scale height in kilometers, which describes the particle vertical distribution. The AOD is then calculated according to

$$
\mathrm{AOD}=\sum_{j} \sigma_{\mathrm{ext}, j} \int_{h_{j, \text { min }}}^{h_{j, \max }} e^{-\frac{h}{Z_{j}}} d h,
$$

where $h_{j, \min }$ is the bottom height of each atmospheric layer, $h_{j, \max }$ is the top height of each layer, and $s_{\text {ext, } j}$ is the extinction coefficient of the layer. To compute the AOD, the user should provide the $Z_{j}$ value and the minimum and maximum heights for each layer. If the scale height is $Z=99 \mathrm{~km}^{-1}$, the software package will consider that the layer is homogenous.

Next, we present a comparison of model runs and actual measurements of how the warming effect of $\mathrm{BC}$ on the atmosphere is modulated by the ambient concentration of sulfates. In particular, we have selected a coastal environment, where BC and sulfates are expected to be more numerous. Sulfate strongly reflects solar radiation, whereas BC strongly absorbs solar radiation. Thus, the net radiative forcing is determined by the relative amount of $\mathrm{BC}$ and sulfate. When $\mathrm{BC}$ and sulfate are in internal mixture, the absorption is amplified with respect to $\mathrm{BC}$ alone. Ramana et al. (2010) measured the influence of the BC-to-sulfate mass concentration ratio on the solar absorption efficiency at $0.55 \mu \mathrm{m}, \alpha$, during the Cheju ABC PlumeAsian Monsoon Experiment (CAPMEX) in the Yellow Sea. This efficiency is related to the SSA through the equation $\alpha=1$-SSA. For comparison, we analyze the measurements for two types of plumes: 1) East Asia $\mathrm{BC}$, whose main source is fossil fuel combustion, and 2) East Asia BC, with biomass fuel as the main source.

For the model input parameters, we consider that $\mathrm{BC}$ is invariably internally mixed with sulfate, as suggested by Ramana et al. (2010). The relative humidity is assumed to be $50 \%$, though it plays a minor role in the results. To model East Asia $\mathrm{BC}$, we consider that the $\mathrm{BC}$ core is in the coarse mode. The coating size is calculated from the BC-to-sulfate mass ratio by considering concentric sphere geometry and the mass densities for $\mathrm{BC}$ and sulfate. Although the chosen parameters are the default ones, the values of a are consistent with those of Ramana et al. (2010) (see Fig. 2).

With respect to South Asian BC, we have also considered internal mixing with sulfate. To the best of our knowledge, an exhaustive characterization of the complex refractive index of biofuel has not been carried out. Therefore, we show for comparison the results for a core of palm oil biodiesel, $m=1.436243$ - i0.002 (Sadrolhosseini et al. 2011) and a core of aged 
biomass, $m=1.54-i 0.018$ (Haywood et al. 2003). The resulting values of a enclose those of South Asian BC, even though the actual refractive index is unknown (see Fig. 2).

CONCLUSIONS. AEROgui is a software package intended to help in the description of the optical properties of aerosols. The components can be both in external mixture-that is, two separate componentsor internal mixture. AEROgui includes various approaches for internal mixture: the shell-and-core model, as well as several mixing rules. Since the refractive index is one of the parameters that cause more uncertainty in the prediction of the aerosols effect, the user can supply values different from those included by default. The interface can run in two modes. One mode is to compute the optical properties of the aerosols in an atmosphere divided into four layers. The other mode, a batch processing, can be used to extensively compute the properties of aerosols. It can also be used to invert the Mie model to infer properties of aerosols with measured optical properties.

To show the potential of the tool, several sensitivity studies have been presented. In particular, we have analyzed the effect on the scattering of the internal mixing of sulfate and BC. We have successfully compared model outputs with actual measurements on the effect of sulfate as a modulator of $\mathrm{BC}$ absorption. More examples can be found in the supplemental material available online.

The software package is also available online (at www.uv.es/pedrose/aerogui).

ACKNOWLEDGMENTS. This work was financed jointly by the Spanish Ministry of Economy and Competitiveness and the European Regional Development Fund through Projects CGL2011-24290 and CGL2012-33294 and by the Valencia Autonomous Government through Projects PROMETEO/2010/064 and ACOMP/2013/205. The collaboration of C. Marcos was possible due to Contract PROMETEO CI10-196.

\section{REFERENCES}

Abo Riziq, A., C. Erlick, E. Dinar, and Y. Rudich, 2007: Optical properties of absorbing and non-absorbing aerosols retrieved by cavity ring down (CRD) spectroscopy. Atmos. Chem. Phys., 7, 1523-1536, doi:10.5194/acp-7-1523-2007.

Alexander, L. V., and Coauthors, 2013: Summary for policymakers. Climate Change 2013: The Physical Science Basis, T. F. Stocker et al., Eds., Cambridge University Press, 3-29.
Aouizerats, B., O. Thouron, P. Tulet, M. Mallet, L. Gomes, and J. S. Henzing, 2010: Development of an online radiative module for the computation of aerosol optical properties in 3-D atmospheric models: Validation during the EUCAARI campaign. Geosci. Model Dev., 3, 553-564, doi:10.5194/gmd-3-553-2010. Aquila, V., and Coauthors, 2011: MADE-in: A new aerosol microphysics submodel for global simulation of insoluble particles and their mixing state. Geosci. Model Dev., 4, 325-355, doi:10.5194/gmd-4-325-2011.

Bauer, S. E., D. Wright, D. Koch, E. R. Lewis, R. McGraw, L.-S. Chang, S. E. Schwartz, and R. Ruedy, 2008: MATRIX (Multiconfiguration Aerosol Tracker of Mixing State): An aerosol microphysical module for global atmospheric models. Atmos. Chem. Phys., 8, 6003-6035, doi:10.5194/acp-8-6003-2008.

Bellouin, N., O. Boucher, J. Haywood, C. Johnson, A. Jones, J. Rae, and S. Woodward, 2007: Improved representation of aerosols for HadGEM2. Hadley Center Tech. Note 73, 43 pp.

- , J. Rae, A. Jones, C. Johnson, J. Haywood, and O. Boucher, 2011: Aerosol forcing in the Climate Model Intercomparison Project (CMIP5) simulations by HadGEM2-ES and the role of ammonium nitrate. J. Geophys. Res., 116, D20206, doi:10.1029/2011JD016074.

Bohren, C. F., and D. R. Huffman, 1983: Absorption and Scattering of Light by Small Particles. John Wiley, $530 \mathrm{pp}$.

Bond, T. C., and R. W. Bergstrom, 2006: Light absorption by carbonaceous particles: An investigative review. Aerosol Sci. Technol., 40, 27-67, doi:10.1080/02786820500421521.

_-, G. Habib, and R. W. Bergstrom, 2006: Limitations in the enhancement of visible light absorption due to mixing state. J. Geophys. Res., 111, D20211, doi:10.1029/2006JD007315.

Cappa, C. D., and Coauthors, 2012: Radiative absorption enhancements due to the mixing state of atmospheric black carbon. Science, 337, 1078-1081, doi:10.1126 /science.1223447.

Chung, S. H., and J. H. Seinfeld, 2005: Climate response of direct radiative forcing of anthropogenic black carbon. J. Geophys. Res., 110, D11102, doi:10.1029/2004JD005441.

Chýlek, P., and J. G. D. Wong, 1998: Erroneous use of the modified Köhler equation in cloud and aerosol physics applications. J. Atmos. Sci., 55, 1473-1477, doi:10.1175/1520-0469(1998)0552.0.CO;2.

—, G. Videen, D. Wally Geldart, J. S. Dobbie, and H. W. Tso, 2000: Effective medium approximations for heterogeneous particles. Light Scattering by Nonspherical Particles: Theory, Measurements, and 
Applications, M. I. Mishchenko, J. W. Hovenier, L. D. Travis, Eds., Academic Press, 273-308.

Creamean, J. M., and Coauthors, 2013: Dust and biological aerosols from the Sahara and Asia influence precipitation in the western U.S. Science, 339, 1572-1578, doi:10.1126/science.1227279.

Fuller, K. A., W. C. Malm, and S. M. Kreidenweis, 1999: Effects of mixing on extinction by carbonaceous particles. J. Geophys. Res., 104, 15941-15954, doi:10.1029/1998JD100069.

Gerber, H., 1985: Relative-humidity parameterization of the Navy Aerosol Model. NRL Rep. 8956, 13 pp.

Hansen, J., M. Sato, and R. Ruedy, 1997: Radiative forcing and climate response. J. Geophys. Res., 102, 6831-6864, doi:10.1029/96JD03436.

Haywood, J. M., S. R. Osborne, P. N. Francis, A. Keil, P. Formenti, M. O. Andreae, and P. H. Kaye, 2003: The mean physical and optical properties of regional haze dominated by biomass burning aerosol measured from the C-130 aircraft during SAFARI 2000. J. Geophys. Res., 108, 8473, doi:10.1029 /2002JD002226.

Hess, M., P. Koepke, and I. Schult, 1998: Optical properties of aerosols and clouds: The software package OPAC. Bull. Amer. Meteor. Soc., 79, 831-844, doi:10.1175/1520-0477(1998)0792.0.CO;2.

Holben, B. N., and Coauthors, 1998: AERONET-A federated instrument network and data archive for aerosol characterization. Remote Sens. Environ., 66, 1-16, doi:10.1016/S0034-4257(98)00031-5.

Jacobson, M. Z., 2000: A physically-based treatment of elemental carbon optics: Implications for global direct forcing of aerosols. Geophys. Res. Lett., 27, 217-220, doi:10.1029/1999GL010968.

_ 2001: Strong radiative heating due to the mixing state of black carbon in atmospheric aerosols. Nature, 409, 695-697, doi:10.1038/35055518.

King, M. D., Y. J. Kaufman, D. Tanré, and T. Nakajima, 1999: Remote sensing of tropospheric aerosols from space: Past, present, and future. Bull. Amer. Meteor. Soc., 80, 2229-2259, doi:10.1175/1520 -0477(1999)0802.0.CO;2.

Köhler, H., 1936: The nucleus in and the growth of hygroscopic droplets. Trans. Faraday Soc., 32, 1152-1161, doi:10.1039/tf9363201152.

Lesins, G., P. Chýlek, and U. Lohmann, 2002: A study of internal and external mixing scenarios and its effect on aerosol optical properties and direct radiative forcing. J. Geophys. Res., 107, 4094, doi:10.1029/2001JD000973.

Levoni, C., M. Cervino, R. Guzzi, and F. Torricella, 1997: Atmospheric aerosol optical properties: A database of radiative characteristics for different components and classes. Appl. Opt., 36, 8031-8041, doi:10.1364 /AO.36.008031.

Ma, N., and Coauthors, 2012: A new method to determine the mixing state of light absorbing carbonaceous using the measured aerosol optical properties and umber size distributions. Atmos. Chem. Phys., 12, 2381-2397, doi:10.5194/acp-12-2381-2012.

Mätzler, C., 2002: MATLAB functions for Mie scattering and absorption, version 2. Institut für Angewandte Physik Res. Rep. 2002-11, 24 pp. [Available online at www.iap.unibe.ch/publications/download/199/en/ý.] Meng, Z., P. Yang, G. W. Kattawar, L. Bi, K. N. Liou, and I. Laszlo, 2010: Single-scattering properties of tri-axial ellipsoidal mineral dust aerosols: A database for application to radiative transfer calculations. J. Aerosol Sci., 41, 501-512, doi:10.1016/j.jaerosci.2010.02.008.

Mishchenko, M. I., L. D. Travis, R. A. Kahn, and R. L. West, 1997: Modeling phase functions for dustlike tropospheric aerosol using shape mixture of randomly oriented polydisperse spheroids. J. Geophys. Res., 102, 16831-16847, doi:10.1029/96JD02110.

Mishra, S. K., S. Dey, and S. N. Tripathi, 2008: Implications of particle composition and shape to dust radiative effect: A case study from the Great Indian Desert. Geophys. Res. Lett., 35, L23814, doi:10.1029/2008GL036058.

Myhre, G., 2009: Consistency between satellitederived and modeled estimates of the direct aerosol effect. Science, 325, 187-190, doi:10.1126 /science.1174461.

- , and Coauthors, 2013: Radiative forcing of the direct aerosol effect from AeroCom phase II simulations. Atmos. Chem. Phys., 13, 1853-1877, doi:10.5194/acp-13-1853-2013.

Nel, A., 2005: Air pollution-related illness: Effects of particles. Science, 308, 804-806, doi:10.1126 /science.1108752.

Ramachandran, S., and R. Srivastava, 2013: Influences of external vs. core-shell mixing on aerosol optical properties at various relative humidities. Environ. Sci.: Processes Impacts, 15, 1070-1077, doi:10.1039 /c3em30975d.

Ramana, M. V., V. Ramanathan, Y. Feng, S.-C. Yoon, S.-W. Kim, G. R. Carmichael, and J. J. Schauer, 2010: Warming influenced by the ratio of black carbon to sulfate and the black-carbon source. Nat. Geosci., 3, 542-545, doi:10.1038/ngeo918.

Ramanathan, V., and G. Carmichael, 2008: Global and regional climate changes due to black carbon. Nat. Geosci., 1, 221-227, doi:10.1038/ngeo156.

Remer, L. A., and Coauthors, 2008: Global aerosol climatology from the MODIS satellite sensors. J. Geophys. Res., 113, D14S07, doi:10.1029/2007JD009661. 
Sadrolhosseini, A. R., M. M. Moksin, W. M. M. Yunus, A. Mohammadi, and Z. A. Talib, 2011: Optical characterization of palm oil biodiesel blend. J. Mater. Sci. Eng., 5, 550-554.

Samset, B. H., and G. Myhre, 2011: Vertical dependence of black carbon, sulfate and biomass burning aerosol radiative forcing. Geophys. Res. Lett., 38, L24802, doi:10.1029/2011GL049697.

Schuster, G. L., O. Dubovik, B. N. Holben, and E. E. Clothiaux, 2005: Inferring black carbon content and specific absorption from Aerosol Robotic Network (AERONET) aerosol retrievals. J. Geophys. Res., 110, D10S17, doi:10.1029/2004JD004548.

Stier, P., J. H. Seinfeld, S. Kinne, and O. Boucher, 2007: Aerosol absorption and radiative forcing. Atmos. Chem. Phys., 7, 5237-5261, doi:10.5194/acp-7-5237-2007.
Wang, J., and S. T. Martin, 2007: Satellite characterization of urban aerosols: Importance of including hygroscopicity and mixing state in the retrieval algorithms. J. Geophys. Res., 112, D17203, doi:10.1029/2006JD008078.

Wex, H., F. Stratmann, T. Hennig, S. Hartmann, and D. Niedermeier, 2008: Connecting hygroscopic growth at high humidities to cloud activation for different particle types. Environ. Res. Lett., 3, 035004 , doi:10.1088/1748-9326/3/3/035004.

Yu, F., G. Luo, and X. Ma, 2012: Regional and global modeling of aerosol optical properties with a size, composition, and mixing state resolved particle microphysics model. Atmos. Chem. Phys., 12, 57195736, doi:10.5194/acp-12-5719-2012.

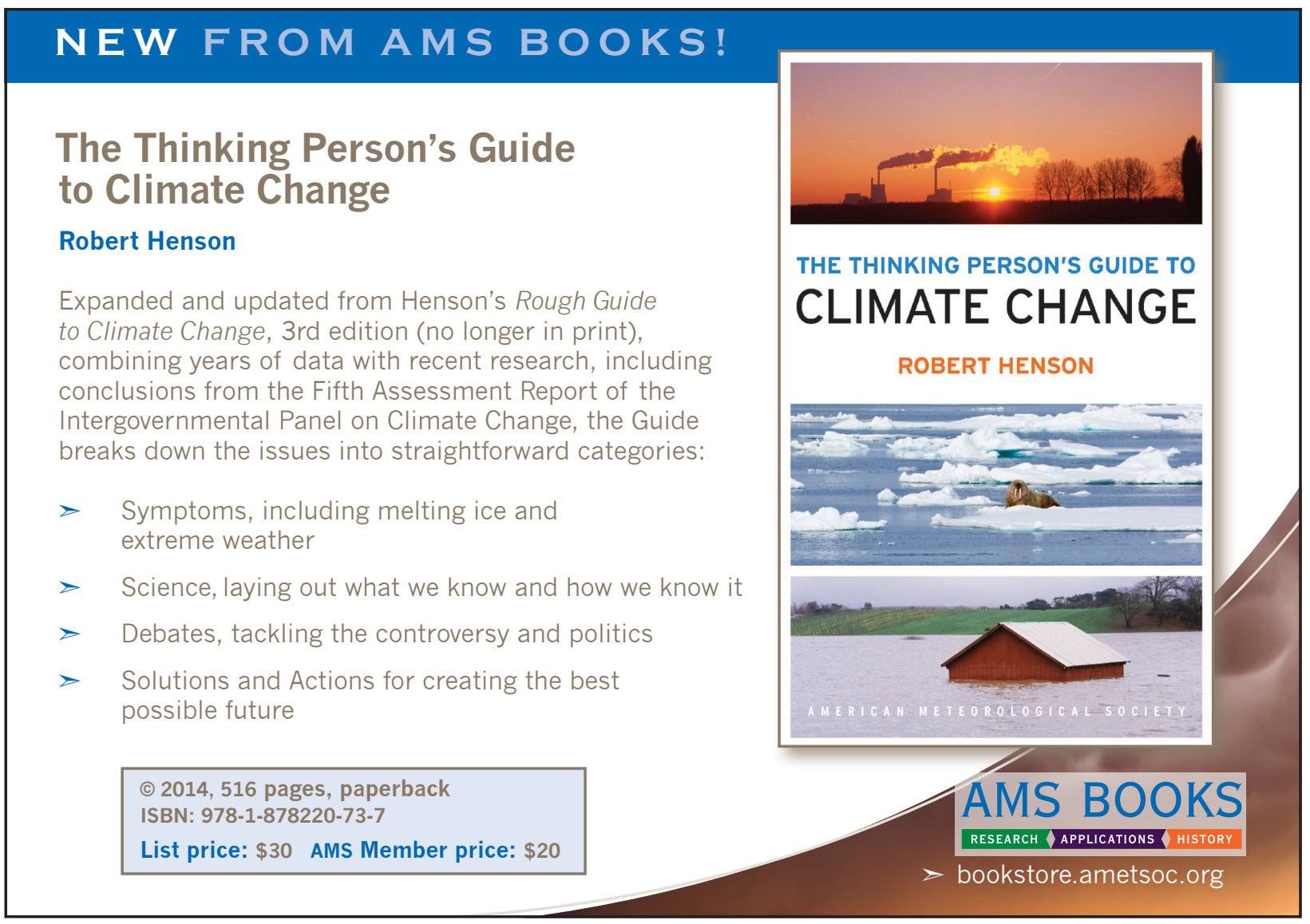

